\title{
Evaluation of regional climate model temperature and precipitation outputs over Scandinavia
}

\author{
Oskar A. Landgren*, Jan Erik Haugen, Eirik J. Førland \\ Norwegian Meteorological Institute, PO Box 43, Blindern, 0313 Oslo, Norway
}

\begin{abstract}
Present-day precipitation and temperature simulations from regional climate models (RCMs) are compared with 2 re-analysis datasets, a hindcast dataset and observations over Scandinavia. The selected RCM data consist of 25 runs from the ENSEMBLES project, the re-analysis datasets are ERA-40 and ERA-Interim from ECMWF, the hindcast is NORA10 from MET Norway, and observations consist of E-OBS gridded data as well as data from meteorological stations. We studied the interannual variability and mean annual temperature and precipitation cycle for 1981 to 2000 and for 2001 to 2012 for 5 locations in Norway and Sweden: Oslo, Bergen, Trondheim, Tromsø and Östersund. The results show rather large differences between models and observations, demonstrating the need for bias adjustment of results from climate models. A model ranking is provided to indicate which model gives the best representation of present climate over Scandinavia. The performance measure used is the root-mean-square deviation of mean and standard deviation of monthly values at the 5 selected locations. The regional models RACMO2 and RCA show the smallest deviations from observed climate. Among the top-ranking model runs, most were driven by the global model ECHAM5 and some by a version of HadCM3. These 2 GCMs are also present among the worst-performing GCM-RCM combinations, indicating that selection of RCMs is crucial. For robust projections, an ensemble mean is still needed.
\end{abstract}

KEY WORDS: RCM · GCM - ENSEMBLES - Scandinavia - Temperature - Precipitation · Evaluation

\section{INTRODUCTION}

Modelling different impacts of climate change often requires accurate Regional Climate Model (RCM) output. For hydrological purposes, climate results need to reproduce the local hydrology for the historical reference period to be applicable to hydrological modelling (Wood et al. 2004). The hydropower industry relies on access to accurate input of meteorological variables in order to, as correctly as possible, model future hydrological states and thus possible power output (e.g. Bergström et al. 2001, Beldring et al. 2008). The meteorological variables of particular interest for input to conceptual hydrological models - such as the HBV model (Bergström, 1976, 1992) - are precipitation and temperature. To model snow accumulation/snow melt in cold cli-

${ }^{*}$ Corresponding author: oskar.landgren@met.no mates, it is crucial to use RCMs providing consistent combinations of temperature and precipitation. In this paper, we present a simple method for users of climate model results to remove the worst-performing models according to different metrics.

As a means of retrieving daily estimates of temperature and precipitation projections locally, global climate model (GCM) runs are dynamically downscaled using RCMs - see e.g. Giorgi et al. (2001). In general, bias adjustment is needed to make the dynamically downscaled data comparable to observations and to produce plausible values of e.g. runoff and streamflow (e.g. Wood et al. 2004). For more information regarding these methods, see e.g. Gudmundsson et al. (2012) or Engen-Skaugen (2007).

RCM performance has been documented in several projects, where the RCMs were driven by reana-

() The authors 2014. Open Access under Creative Commons by Attribution Licence. Use, distribution and reproduction are unrestricted. Authors and original publication must be credited. 
lysis data in addition to GCM results. For the European domain in the ENSEMBLES-project (www. ensembles-eu.org) (van der Linden \& Mitchell 2009), the full model ensemble driven by ERA40 was evaluated for the period 1961 to 2000 (Kjellström et al. 2010), and for North America, in the NARCCAP program, 6 RCMs driven by NCEP reanalysis were evaluated for the period from 1980 to 2004 (Mearns et al. 2012). Reanalysis simulations may be used in a biasadjustment procedure of GCM-driven experiments to assign RCM-specific errors, while the GCM-driven experiments for present climate contains other sources of uncertainty as well, e.g. natural climate variability and GCM-specific features. In the PRUDENCE project by Jacob et al. (2007), an 11-member RCM ensemble driven by HadAM3H and ARPEGE was evaluated for 1961 to 1990 over multiple European regions, including Scandinavia, detailing seasonal performance in temperature and precipitation compared to gridded observations from the Climatic Research Unit (www.cru.uea.ac.uk). Over the same regions and time period, Boberg et al. (2010) compared precipitation for 7 ENSEMBLES models and found improvements in the ensemble as a whole as well as in individual models when comparing with the PRUDENCE ensemble. There are studies of global model performance in high latitudes (e.g. Walsh et al. 2008 and Overland et al. 2011) and over Europe (e.g. Cattiaux et al. 2012, Bladé et al. 2012). There are numerous evaluations of individual models, e.g. Jones et al. (2004) and Kjellström et al. (2011) for the Rossby Centre Atmospheric model.

To obtain a signal of the uncertainty and spread in climate predictions, multiple models can be run and results compared. While users ideally may need to revise their methods to be less dependent on individual model runs and more on ensemble statistics. They often end up using a small selection of model data because the computational time associated with running all GCM-RCM-hydrological model combinations necessitates narrowing down to fewer models. The large spread in the climate model results represents a challenge for decision makers; e.g. the hydro-power industry wants recommendations on the optimum GCM-RCM model run combinations. Giving such recommendations is not straightforward.

Numerous dynamically downscaled GCM runs are available from different international collaborations. This study focusses on results from the large European project ENSEMBLES, which was supported by European Commission's 6th Framework Programme as a 5 yr Integrated Project (2004 to 2009). The aim of the ENSEMBLES project was to evaluate different
RCM runs covering the same region (domain). This provided uncertainty measures from climate models in a way similar to how an ensemble of model runs work in numerical weather prediction. The regional models were forced with boundary conditions from GCMs available from the CMIP3 project (Meehl et al. 2007), 3 separate GCM runs from UK MetOffice Hadley Centre (Collins et al. 2011) and 1 ARPEGE run from Météo France.

To obtain recommendations, we consider a large ensemble of model runs. One way of dealing with such data sets is to use the average of all ensemble members. This would be ideal if all members were independent and none had bigger errors than any other. However, some models share the same representation of e.g. the model physics, and are therefore not independent; and in the ENSEMBLES datasets, some of the global models (notably ECHAM5 and HadCM3) were used more often than the others.

There have been attempts to produce a weighted average according to different metrics, and the matter has been discussed in the ENSEMBLES Final Report (van der Linden \& Mitchell 2009, Chap. 6) as well as by e.g. Founda \& Giannakopoulos (2009) and Fowler \& Ekström (2009). Weighting is subjective, and it has been concluded by e.g. Fowler \& Ekström (2009) that it does not improve the results a great deal, possibly due to lack of model independence and lateral boundary conditions. Christensen et al. (2010) did not find compelling evidence of an improved description of mean climate states using performance-based weights in comparison to the use of equal weights. Kjellström et al. (2010) found improvements in results when using individual weights but stressed that weights should not be based on overall performance measures but rather depend on application, with different weights for different regions, seasons, variables, etc. In this study, we do not attempt to give recommendations on how many members the user should look at. For global model selection, a procedure and some considerations regarding ensemble size are discussed by Overland et al. (2011).

Here, we have chosen to evaluate the models against recent historical data covering the Scandinavian region. Care must be taken when applying conclusions to future periods, since the performance for historical periods does not necessarily have to correspond to the performance for future periods. According to Racherla et al. (2012), a skillful prediction of climatology is not strongly related to skill in predicting trends and climate change. Christensen et al. (2008) analysed the bias of the ENSEMBLES data 
when driven with ERA40 over 8 regions, including Scandinavia, finding that the bias increases with increasing temperature, which highlights the difficulties related to bias-adjustment.

To provide an assessment of the performance over the Scandinavian peninsula and to be able to give advice regarding which RCM run to use, all RCM runs available from the ENSEMBLES project were evaluated against the re-analysis datasets as well as observations for a given reference period. Results at 5 selected stations (Fig. 1) - Oslo-Blindern, BergenFlorida, Trondheim-Værnes, Tromsø in Norway and Östersund-Frösön in Sweden-are considered (for details, see Table 3). The annual cycle for the gridded datasets is also presented for comparison. Despite being close to the coast (especially Bergen-Florida

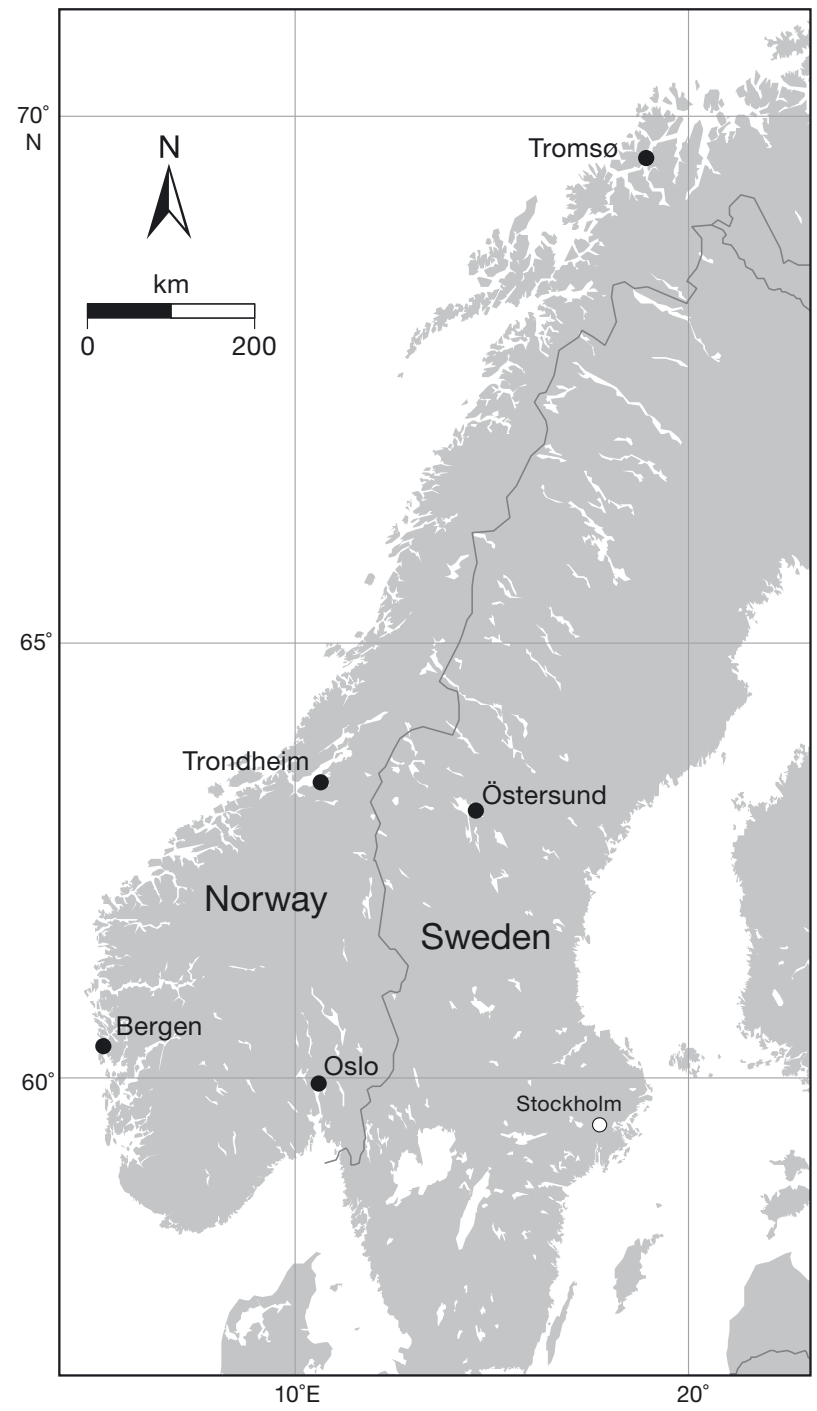

Fig. 1. The spatial region used in this study, $2^{\circ}$ to $23^{\circ} \mathrm{E}$, $56^{\circ}$ to $71^{\circ} \mathrm{N}$, including the 5 station locations. Map COpenStreetMap contributors and Tromsø), all 5 stations are located on land points in the model domain.

An evaluation of the GCMs and RCMs used is presented by Landgren et al. (2012), including a short description of the magnitude of the climate change signal on temperature and precipitation over Scandinavia and the 5 selected locations. Climate projections covering the Norwegian mainland are discussed in more detail by Hanssen-Bauer et al. (2009).

\section{DATA}

The data used in this study consisted of model data from RCM runs as well as re-analyses, hindcasts and observational data. The variables used were the $2 \mathrm{~m}$ temperature (known as T2m or TAS) and total precipitation (PR).

\subsection{Re-analyses and hindcasts}

Since there is no such thing as a global (or even regional) observation dataset that perfectly covers the whole area of interest with high spatial and temporal resolution, we cannot directly compare models to observations. Instead, re-analysis datasets are created from models using different observation types as input, in an optimal way, to fill in the gaps in space and time.

The European Centre for Medium-Range Weather Forecasts (ECMWF) provides re-analyses of presentday climate. The ECMWF products used in this study are the monthly means from the $40 \mathrm{yr}$ re-analysis (ERA-40, Uppala et al. 2005) and Interim re-analysis (ERA-Interim, Dee et al. 2011). Although available in higher temporal resolutions, for this study monthly values are used.

Accompanying the ENSEMBLES RCM data was also a daily gridded observational dataset, E-OBS (Haylock et al. 2008), covering Europe on the same grid as the models. The dataset is provided by the European Climate Assessment and Dataset (ECA\&D) project (http://eca.knmi.nl). This dataset contains only data over land and is based upon a sparse station network. The E-OBS data is given as daily values, so monthly values were created by taking the mean (for temperature) and sum (for precipitation) for each month.

NORA10 is a hindcast project produced at MET Norway in which the numerical weather prediction model HIRLAM is used to downscale ERA-40 data to $0.1^{\circ}$ resolution over Norway and adjacent sea areas. 
The dataset originally covered the ERA-40 period, until 2002, but has since been extended using data from the ECMWF Integrated Forecast System (IFS) operational analyses (Reistad et al. 2011, Haakenstad et al. 2012). The different re-analyses or hindcast runs used in the present study are listed in Table 1.

\subsection{Regional climate models}

RCMs provide a higher spatial resolution (here, typically 25 to $50 \mathrm{~km}$ ) than global models, and thus include representation of several smaller-scale processes that are not included in global models. The process of simulating higher-resolution parameters from lower using numerical models is called dynamical downscaling. Regional models, as the name implies, are typically only run for a region, although the size can vary from just a few hundred kilometres up to continental scale. A prerequisite for regional models is that the spatial and temporal range of inter- est should be covered by a global model, whose data then acts as boundary conditions for the regional model. Therefore, the lists of GCMs and RCMs available form a matrix with an increasing number of combinations of GCMs and RCMs.

RCM runs available from the ENSEMBLES project are used. The model combinations used are listed in Table 2.

Most models were run in $25 \mathrm{~km}$ resolution (some of the runs from KNMI and SMHI are $50 \mathrm{~km}$ ) and time periods within the range 1950 to 2050 (2100). A more detailed description can be found in the GCM/RCM matrix at the ENSEMBLES website (http://ensemblesrt3.dmi.dk/GCM-RCM-matrix.xls). For the Hadley Centre global climate model (HadCM3), multiple runs are represented by 3 different climate sensitivities $(\mathrm{Q} 0=$ normal sensitivity, 3.50K; Q3 = low sensitivity, 2.52K; and Q16 = high sensitivity, 5.46K). The SMHI RCA $50 \mathrm{~km}$ run was omitted from this study because of difficulties with coordinate transformations.

Table 1. Gridded observational datasets used in the present study

\begin{tabular}{|lccccc|}
\hline Dataset name & Provider & Time range & Spatial resolution & Temporal resolution & Comments \\
\hline ERA-40 & ECMWF & Sep 1957 - Aug 2002 & $2.5^{\circ} \times 2.5^{\circ}$ & Monthly mean & \\
ERA-Interim & ECMWF & $1979-$ present & $0.75^{\circ} \times 0.75^{\circ}$ & Monthly mean & Daily mean \\
E-OBS & ECA\&D & $1950-$ present & $0.25^{\circ} \times 0.25^{\circ}$ & Covers land only \\
NORA10 & MET Norway & Sep 1957- present & $0.1^{\circ} \times 0.1^{\circ}$ & Hourly mean & Forced by ERA-40 and IFS \\
aData converted to monthly means after download & & & \\
\hline
\end{tabular}

Table 2. Models used in the ENSEMBLES project. Some RCMs are run for $>1$ GCM

\begin{tabular}{lllcl|}
\hline Country & Institute & \multicolumn{1}{c}{ Driving GCMs } & RCM & \multicolumn{1}{c}{ RCM reference } \\
\hline Ireland & C4I & ECHAM5, HadCM3Q16 & RCA3 & Kjellström et al. (2005) \\
France & CNRM & ARPEGE & Aladin & Radu et al. (2008) \\
Denmark & DMI & ARPEGE, ECHAM5, BCM & HIRHAM & Christensen et al. (1996) \\
Switzerland & ETHZ & HadCM3Q0 & CLM & Böhm et al. (2006) \\
Germany & GKSS & IPSL & CLM & Böhm et al. (2006) \\
UK & HC & HadCM3Q0, HadCM3Q3, HadCM3Q16 & HadRM3 & Collins et al. (2006) \\
Italy & ICTP & ECHAM5 & RegCM & Giorgi \& Mearns (1999) \\
Netherlands & KNMI & ECHAM5, MIROC3.2-hires & RACMO & van Meijgaard et al. (2008) \\
Norway & METNO & BCM, HadCM3Q0 & HIRHAM & Christensen et al. (1996), \\
& & & & Roeckner et al. (1996), \\
Germany & MPI & ECHAM5 & REMO & Jacob (2001), Jacob et al. (2001) \\
Canada & OURANOS & CGCM3 & CRCM & Plummer et al. (2006) \\
Sweden & SMHI & ECHAM5, BCM, HadCM3Q3 & RCA & Kjellström et al. (2005) \\
Spain & UCLM & HadCM3Q0 & PROMES & Sanchez et al. (2004) \\
Russia & VMGO & HadCM3Q0 & RRCM & Shkolnik et al. (2000) \\
\hline
\end{tabular}




\subsection{Temperature and precipitation stations}

The variables used were monthly means of temperature and monthly precipitation totals. To validate the RCMs, 5 high-quality stations representing different climate regions were chosen. For Norway, Hanssen-Bauer et al. (2003) identified 6 regions within which the long-term developments of standardized monthly temperatures are similar. From each of the 4 largest regions, 1 representative station with long-term climate records was selected. The Swedish station Östersund was chosen to include 1 site east of the Swedish-Norwegian mountain divide. The Norwegian data were available from the Norwegian Meteorological Institute (www.met.no), while data from the Swedish station (Östersund-Frösön) were available from the Swedish Meteorological and Hydrological Institute (www.smhi.se). The station locations are shown in Fig. 1. More information regarding the locations, IDs as well as altitude and time period available is presented in Table 3 .

\section{METHODS}

To visualise and quantify the differences between the models, the data was studied in terms of values at the selected locations, as well as spatial averages over all of Scandinavia. Since climate models develop their own climatology, a specific month should not necessarily relate exactly to the corresponding measured point in time from observations. Instead, the overall statistics (mean, distribution, etc.) are comparable. For this reason, when comparing the model data with observations or re-analysis in this work, mean monthly values over a multi-year interval are used.

The procedures of data retrieval, selection of spatial and temporal subsets, and different data analysis steps are detailed by Landgren et al. (2012).

For the reference period 1981-2000, data for each of the 12 months was selected, and the mean values were calculated in order to compare the individual RCM runs to the ERA-40, ERA-Interim, NORA-10 and the E-OBS datasets. This was done for each of the 5 locations.

Inspired by the model-ranking tables in e.g. Walsh et al. (2008) and Overland et al. (2011), the model performance ranking was presented as integrated rank indices from individual performance tests. Compared to Christensen et al. (2010), who used 6 different performance metrics, for this study, the representation of annual cycle and inter-annual variability were considered the most important for hydrological purposes. After calculating the rootmean-square deviation (RMSD) of a model from a reanalysis or observational dataset, its value was compared to the values of the other models. The inter-annual variability was calculated as the standard deviation (SD) for each month (e.g. 20 January values for 1981-2000) for each model and reference dataset. For the temperature, the difference between the model SD and reference data SD were used, while for precipitation, it was calculated based on the method of de Elía et al. (2013). Here, it is taken as follows:

$\frac{\mathrm{SD}_{\text {model }}}{\mathrm{SD}_{\text {ref }}}$ if $\mathrm{SD}_{\text {ref }}>\mathrm{SD}_{\text {model }}$, or $1-\frac{\mathrm{SD}_{\text {ref }}}{\mathrm{SD}_{\text {model }}}$ if $\mathrm{SD}_{\text {model }}>\mathrm{SD}_{\text {ref }}$

The root-mean-square is then taken over the 12 values (one for each month) to produce a single value representative of the deviation from observed interannual variability.

The model with the lowest error was ranked as 1, and the others followed in order. This was done for each of the 5 locations and the 2 parameters (TAS and PR), giving 10 tests in total. The ranks for the different tests were summed up to form integrated rank indices. From these, a total rank of the models was found. If 2 or more models ended up with the same score, they were both given the higher numbered rank, e.g. if there was a tie for the first place, both were given position 2 .

Table 3. Weather stations used in this study

\begin{tabular}{|c|c|c|c|c|c|c|c|c|}
\hline WMO ID & $\begin{array}{l}\text { MET Norway } \\
\text { ID }\end{array}$ & Area & Station name & ${ }^{\circ} \mathrm{E}$ & ${ }^{\circ} \mathrm{N}$ & $\begin{array}{l}\text { Altitude } \\
\text { (m a.s.l.) }\end{array}$ & Since year & Comments \\
\hline 011492 & 18700 & Oslo & Blindern & 10.7 & 59.9 & 94 & 1937 & \\
\hline 013170 & 50540 & Bergen & Florida & 5.3 & 60.4 & 12 & 1957 & PR since 1983 \\
\hline 012710 & 69100 & Trondheim & Værnes & 10.9 & 63.5 & 12 & 1946 & \\
\hline 01026 & 90450 & Tromsø & - & 18.9 & 69.7 & 100 & 1920 & \\
\hline 020620 & SMHI 13411 & Östersund & Frösön & 14.5 & 63.2 & 376 & 1961 & From SMHI \\
\hline
\end{tabular}




\section{RESULTS}

\subsection{Model ranking}

The RMSD of the annual cycles and inter-annual variability were calculated for each of the 12 months, and the values were compared in each of the 5 locations as shown in Table 4.

Using the RMSD data from observations (Table 4), statistics can be derived to compare the ensemble overall performance at the 5 selected locations. Minimum, 1st quartile, median, mean, 3rd quartile, maximum values and SD for temperature and precipitation are presented in the lower part of the table. The ranking for all 5 stations combined is shown in Table 5. Due to the fact that output from the ETHZ CLM HadCM3Q0 run does not contain data far enough north, the ranks for this model (shown in italics) have been calculated without Tromsø, and thus, the ranks are not directly comparable to the rest of the table. Similarly, the ranks for all other models have been calculated including Tromsø but excluding ETHZ so that the number of ensemble members and maximum rank is 24 .

\subsection{Annual cycle at the selected locations}

Mean monthly values of temperature and precipitation from the $25 \mathrm{RCM}$ runs for the 5 locations are shown in Figs. $2 \& 3$. The 3 model combinations KNMI RACMO2 ECHAM5, KNMI RACMO2 MIROC3.2-hires and SMHI RCA ECHAM5 are highlighted with dashed lines. These were selected due to high ranking (Table 5) when comparing with observations. For KNMI RACMO2 ECHAM5, there were 3 runs with similar results, but only Run 1 was selected.

\subsection{Inter-annual variability}

The inter-annual variability for the 5 stations is shown in Fig. 4 (temperature) and Fig. 5 (precipitation).

\section{DISCUSSION}

\subsection{Model ranking}

The RMS deviation of the mean annual cycle for the period 1981 to 2000 in RCMs compared to observations is presented in Table 4 . The underlying annual cycle data is presented in Section 4.2. For some model runs, there are large differences between RCM control runs and observations, up to $9.2^{\circ} \mathrm{C}$ for Tromsø for the OURANOS-MRCC-CGCM3 run. Interestingly, this model run shows among the best representations of the precipitation cycle, while at the same time being among the poorest for temperature. This emphasises that for combined temperature-precipitation studies (e.g. hydrology), no model should be selected because of good performance for only 1 variable.

The overall ranking is similar whether the analysis is done over the whole Scandinavian domain (Landgren et al. 2012; Table 4) or at the 5 selected locations. Most ECHAM5-based runs show good results and so do some HadCM3-based runs. The 3 model combinations with lowest deviation from observed values during the period 1981 to 2000 are KNMI RACMO2 MIROC3.2-hires, SMHI RCA ECHAM5 and KNMI RACMO2 ECHAM5. This is in agreement with Kjellström et al. (2010), who determined that, for Scandinavia, RACMO2 and RCA were the best-performing RCMs for a compound weight metric. These 3 may represent the Scandinavian climate best according to our tests, but we do not recommend constructing an ensemble using only these 3 model runs, particularly since 2 of them share the same GCM. When choosing members for a small ensemble, users should pay attention to cover the uncertainty range e.g. from differences in global climate sensitivity as well as consult the references mentioned in Section 1. The same analysis was performed for the period January 2001 to May 2012 with similar results, as shown in Table 5. For these combinations, the driving GCMs are related to the findings of Walsh et al. (2008), where ECHAM5, MIROC3.2 (medres) and HadCM3 were among the top 4 GCMs when comparing temperature, precipitation and sea-level pressure over Alaska and Greenland as well as latitudes $60^{\circ}$ to $90^{\circ}$ and $20^{\circ}$ to $90^{\circ}$.

The statistics presented in the lower part of Table 4 show small differences in ensemble median values among the 5 locations. The median temperature deviation from observed values is lowest for Östersund-Frösön and Oslo-Blindern, while the median precipitation deviation is highest for the same locations. For the minimum, median and mean values as well as the first and third quartile, the highest values for temperature deviation are found in TrondheimVærnes and for precipitation in Östersund-Frösön. Bergen-Florida has lowest deviations for precipitation, except for minimum and maximum values, but the fact that this location has the highest absolute 


\begin{tabular}{|c|c|c|c|c|c|c|c|}
\hline \multirow{8}{*}{ 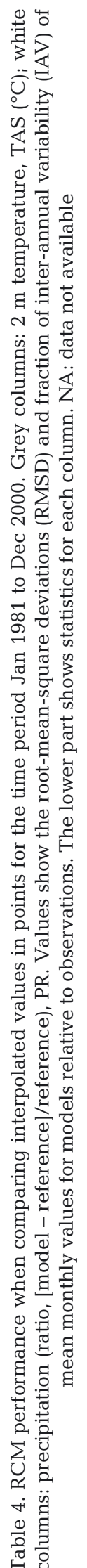 } & & \multirow{2}{*}{\multicolumn{3}{|c|}{ 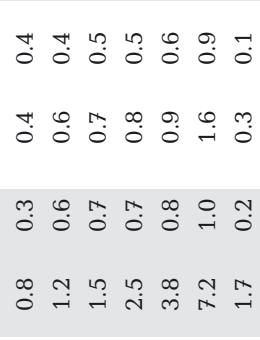 }} & & \\
\hline & & & & & & & \\
\hline & \multirow{6}{*}{\multicolumn{2}{|c|}{ 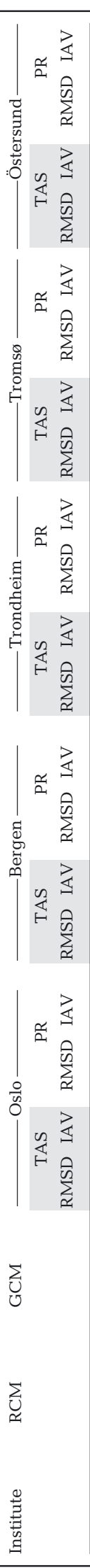 }} & & & & & \\
\hline & & & & & & & 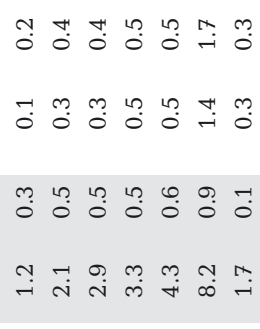 \\
\hline & & & & & & & 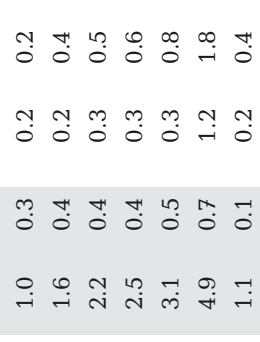 \\
\hline & & & & & & & 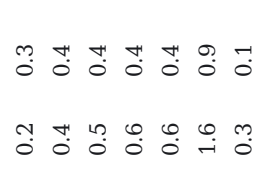 \\
\hline & & & & & & & 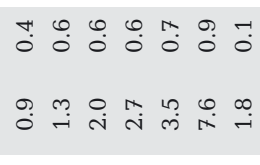 \\
\hline & & & \multicolumn{3}{|r|}{ 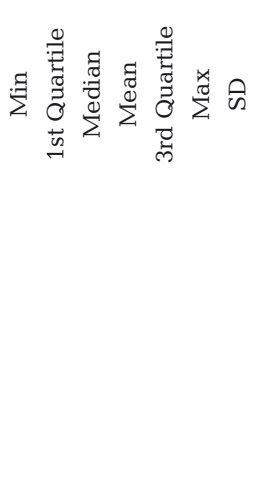 } & & \\
\hline
\end{tabular}




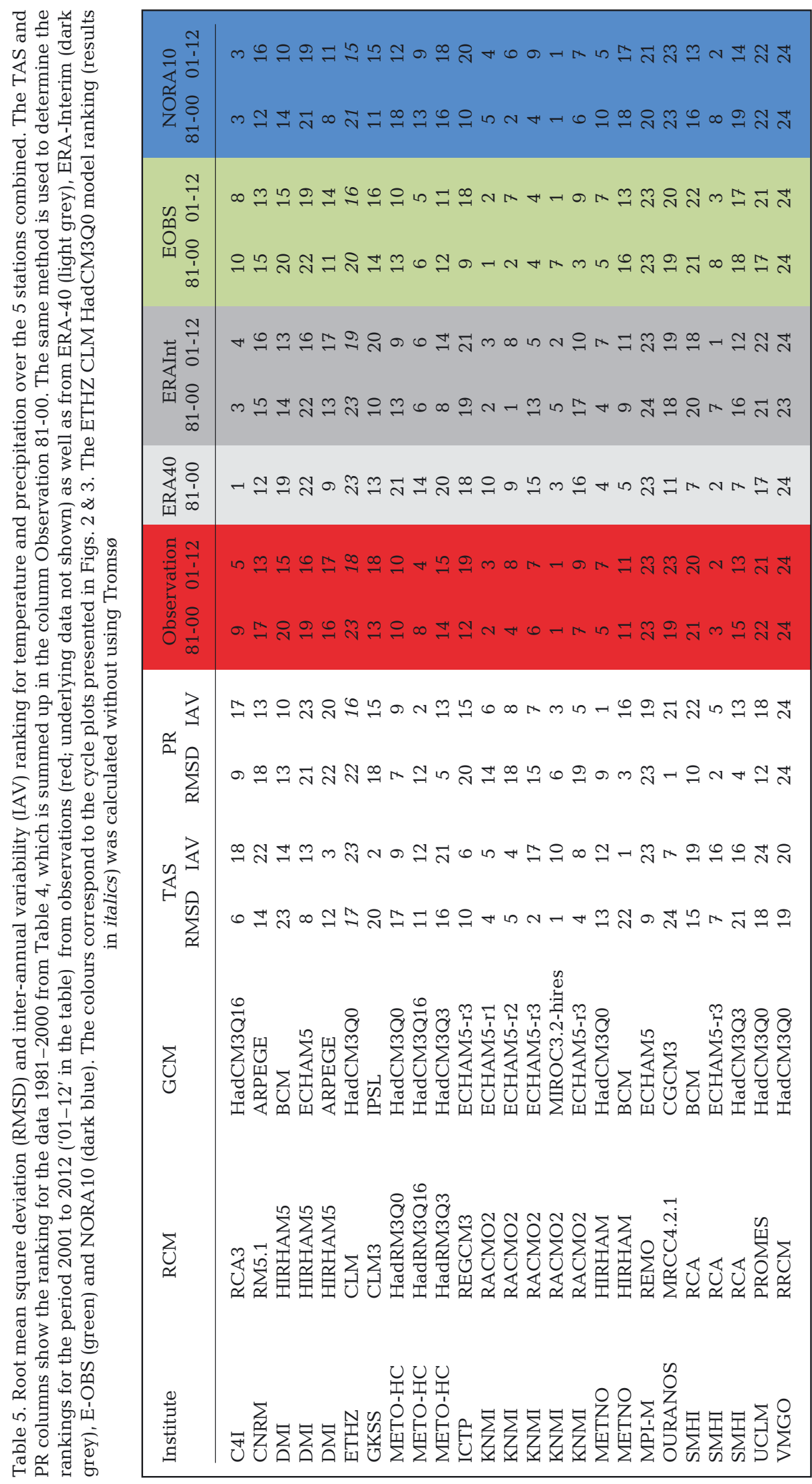

values indicates that the performance would be different if using absolute values rather than using a ratio.

\subsection{Annual cycle}

When studying the annual temperature cycles in Fig. 2, the majority of the models seem to give temperatures that are too low compared to observations, especially for the winter season. Exceptions are KNMI-RACMO2MIROC3.2-hires, which overestimates the summer temperature by $\sim 2^{\circ}$ for all locations, and MPIM-REMO-ECHAM5, which overestimates winter temperature by almost $5^{\circ}$ for all locations. For the area studied, we may advise against OURANOS MRCC4.2.1 CGCM3 and the 2 HIRHAM$\mathrm{BCM}$ runs due to cold biases. The cold biases in MRCC can be related to the bias in daily minimum temperature (Kjellström et al. 2010) and could be caused by e.g. failure to represent inversions on the coarse vertical scale. The HIRHAM-BCM temperature may be influenced by incorrect representation of sea ice. (The SMHI RCA-BCM run scores better, illuminating that the performance of one GCM may differ between different RCM downscalings.)

For the precipitation cycles in Fig. 3, the models show a large spread. Many models greatly overestimate precipitation for most locations and seasons (e.g. VMGO-RRCM-HadCM3Q0, MPIM-REMO-ECHAM5 and DMI-HIR HAM5-ECHAM5). Runs based on BCM seem to underestimate precipitation for the 3 locations on the Norwegian coast (BergenFlorida, Trondheim-Værnes and Tromsø), especially in the summer months. 

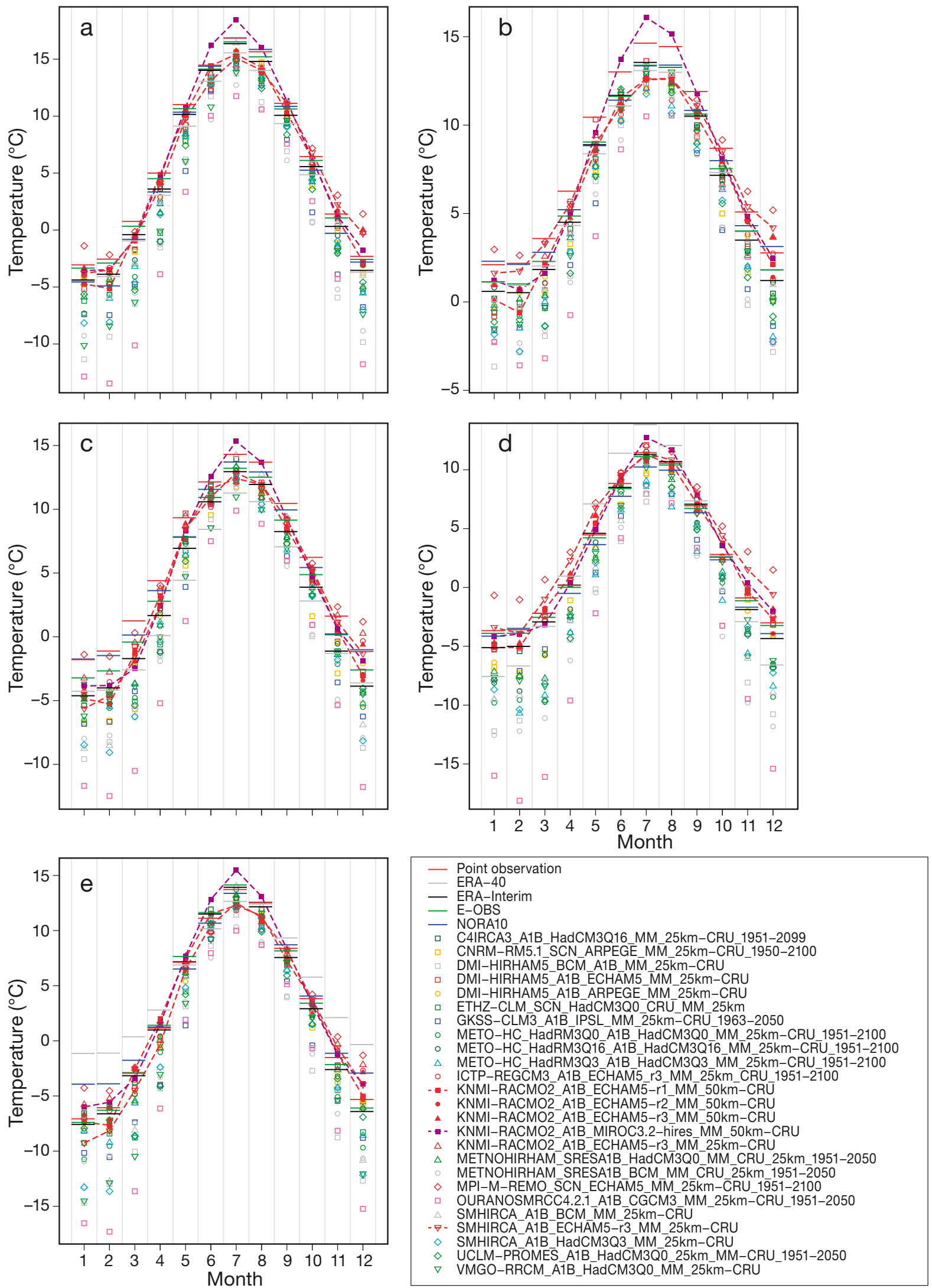

Fig. 2. Mean monthly temperature at (a) 18700 Oslo-Blindern, (b) 50540 Bergen-Florida, (c) 69100 Trondheim-Værnes, (d) 90450 Tromsø, and (e) 13411 Östersund-Frösön for the reference period 1981 to 2000. The driving GCMs for ENSEMBLES are colourcoded: ARPEGE (yellow), BCM (grey), CGCM3 (magenta), ECHAM5 (red), HadCM3Q0 (light green), HadCM3Q3 (light blue), HadCM3Q16 (dark green), IPSL (blue) and MIROC3.2 (purple). Filled symbols represent the $50 \mathrm{~km}$ resolution, while unfilled symbols are $25 \mathrm{~km}$ 

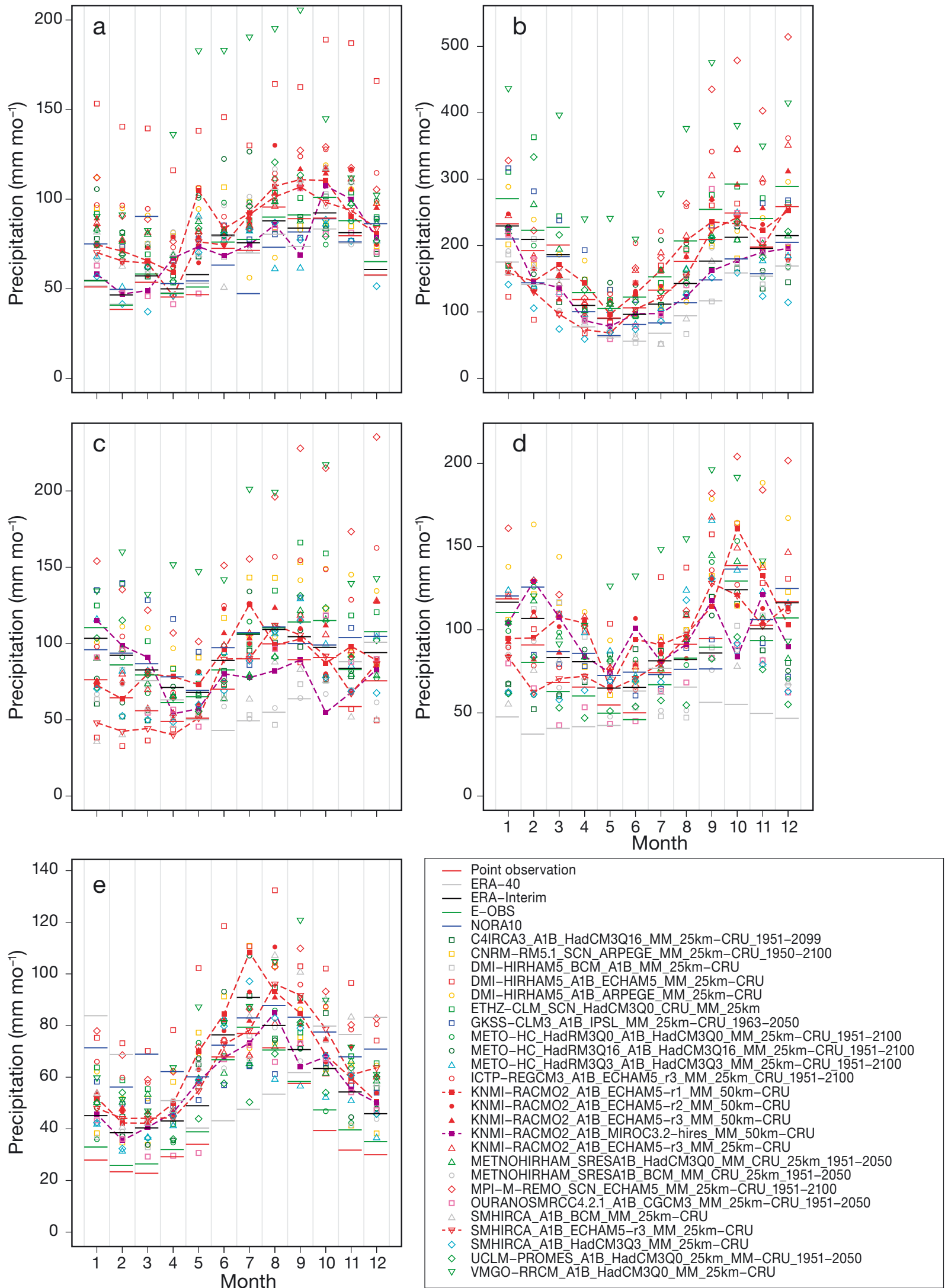

Fig. 3. Mean monthly precipitation at (a) 18700 Oslo-Blindern, (b) 50540 Bergen-Florida, (c) 69100 Trondheim-Værnes, (d) 90450 Tromsø, and (e) 13411 Östersund-Frösön for the reference period 1981 to 2000. The driving GCMs for ENSEMBLES are colourcoded: ARPEGE (yellow), BCM (grey), CGCM3 (magenta), ECHAM5 (red), HadCM3Q0 (light green), HadCM3Q3 (light blue), HadCM3Q16 (dark green), IPSL (blue) and MIROC3.2 (purple). Filled symbols represent the $50 \mathrm{~km}$ resolution, while unfilled symbols are $25 \mathrm{~km}$ 

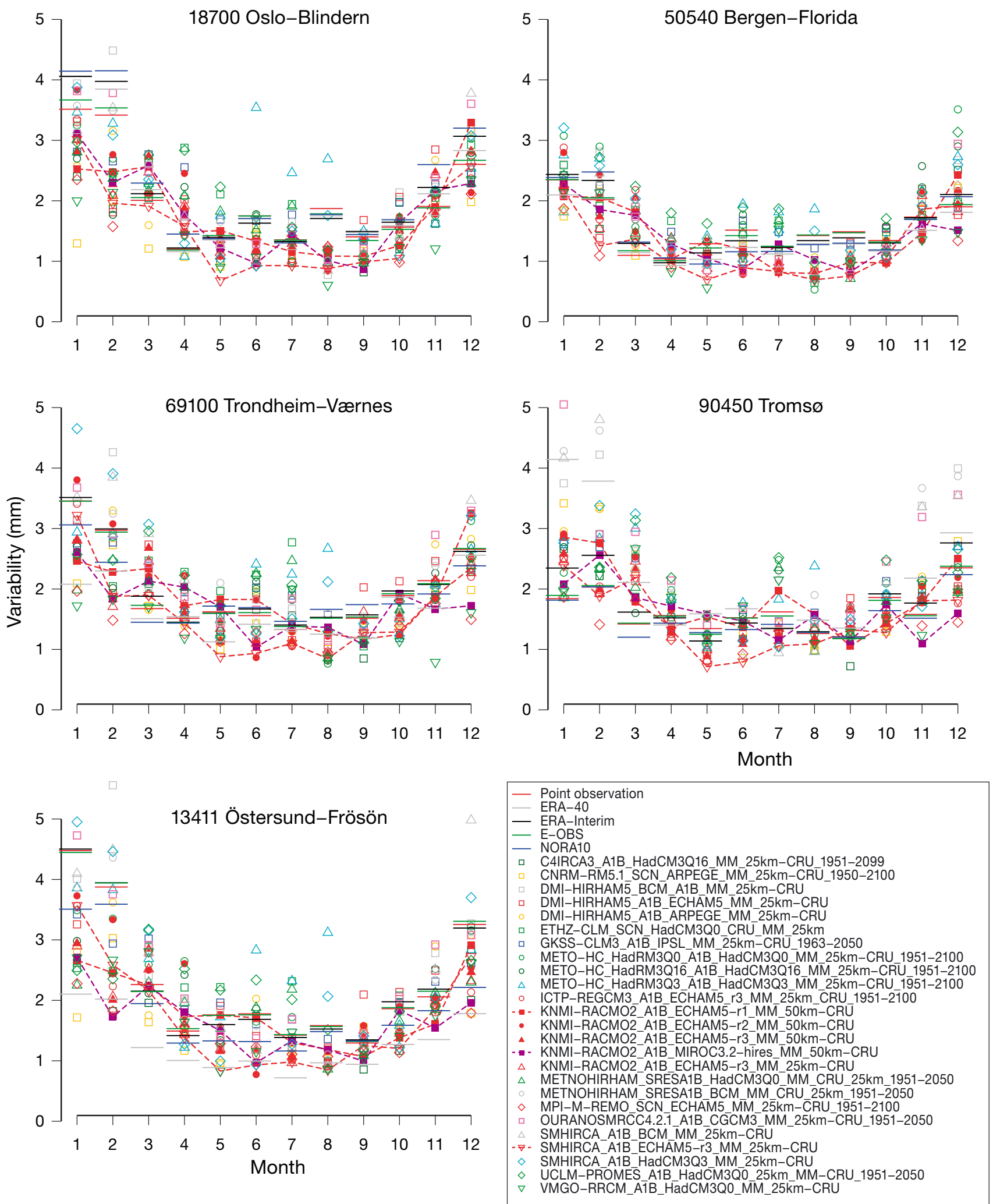

Fig. 4. Inter-annual variability of temperature $\left({ }^{\circ} \mathrm{C}\right)$ for the period 1981 to 2000. The driving GCMs for ENSEMBLES are colourcoded: ARPEGE (yellow), BCM (grey), CGCM3 (magenta), ECHAM5 (red), HadCM3Q0 (light green), HadCM3Q3 (light blue), HadCM3Q16 (dark green), IPSL (blue) and MIROC3.2 (purple). Filled symbols represent the $50 \mathrm{~km}$ resolution, while unfilled symbols are $25 \mathrm{~km}$ 

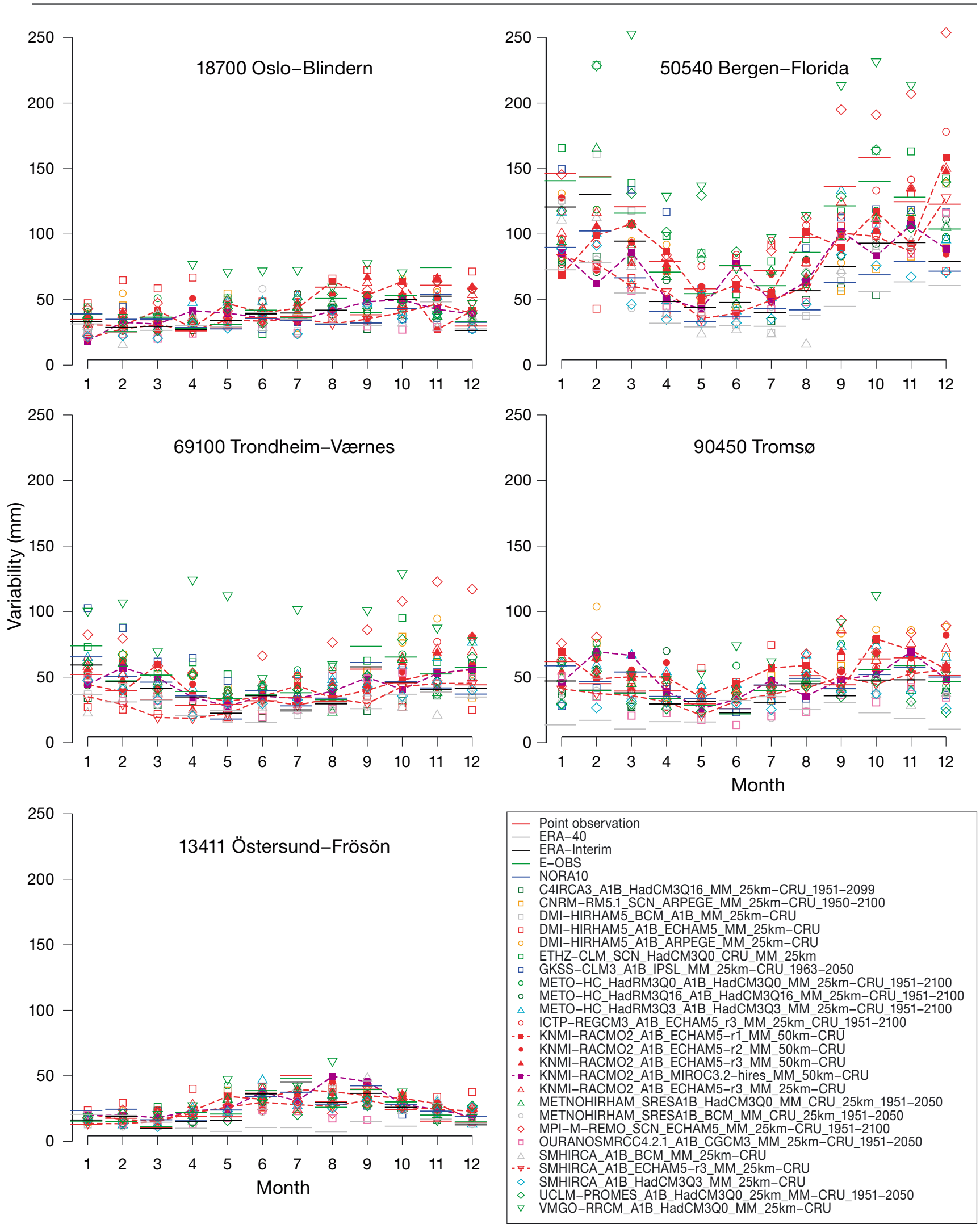

Fig. 5. Inter-annual variability of precipitation for the period 1981 to 2000. The driving GCMs for ENSEMBLES are colourcoded: ARPEGE (yellow), BCM (grey), CGCM3 (magenta), ECHAM5 (red), HadCM3Q0 (light green), HadCM3Q3 (light blue), HadCM3Q16 (dark green), IPSL (blue) and MIROC3.2 (purple). Filled symbols represent the $50 \mathrm{~km}$ resolution, while unfilled symbols are $25 \mathrm{~km}$. For VMGO-RRCM-HadCM3Q0, very high values for January (344 mm) and February (500 mm) 
There are, however, considerable differences, especially for precipitation but also for temperature, between observational, re-analysis and hindcast datasets. Table 5 provides an idea of how the model performance changes depending on which dataset is chosen as reference. The ranks for multiple references have not been merged to a single score as it would be equivalent to trying to achieve cycles resembling the average of the reference datasets.

For Oslo-Blindern and particularly ÖstersundFrösön, most models seem to overestimate wintertime precipitation. This may partly be due to undercatch in the precipitation gauges during events with snowfall and high winds (Førland \& Hanssen-Bauer 2000).

\subsection{Interannual variability}

For all 5 stations, the highest temperature variability is in the winter months, as shown in Fig. 4. The model ensemble manages to lie around the observed temperature variability for most months, but the winter season (December to February) is a challenge, with under-representation in Oslo-Blindern and ÖstersundFröson and over-representation in Tromsø. There is a slight overestimation in variability in March and April, which may be related to snow melt.

The precipitation variability (Fig. 5) is frequently overestimated by some models, notably VMGORRCM-HadCM3Q0 and MPI-M-REMO-ECHAM5 in Bergen-Florida and Trondheim-Værnes. Because of its overestimation of precipitation both in mean and variability, we recommend against using the VMGORRCM-HadCM3Q0 run. There is also a clear difference between the reference datasets: ERA-40 and NORA10 have less variability for most months and sites than observations, ERA-Interim and E-OBS.

A comparison done point by point may be misleading, so care should be taken when generalising the results. In particular, the variability from a pointbased measurement will not necessarily correspond to the variability of values taken from a grid, since each grid cell represents a certain area.

\subsection{Literature comparison and other considerations}

In the literature, analyses of the performance of RCM model runs over Scandinavia have been performed e.g. using the domains from PRUDENCE, which included a Scandinavian domain. Boberg et al. (2010) evaluated the probability distribution function of precipitation from 7 of the ENSEMBLES RCMs as well as comparing with the same method using the PRUDENCE data. Using this subset of models, the observed PDFs of daily precipitation from ECA\&D stations in Scandinavia from 1961 to 1990 were best represented by METO-HC-HadRM3-HadCM3Q0, KNMI-RACMO2-ECHAM5 and MPI-M-REMOECHAM5. While the first of these 2 rank well in Table 5 for the precipitation scores, the third ranks 23 and 21 for RMSD and IAV respectively. This could be either due to different stations, the time period or the time resolution used.

Jones et al. (2004) evaluated the RCA model and found that it produces overly frequent precipitation for Scandinavia. Kjellström et al. (2011) studied the RCA3 model using different driving data and found that the biases are larger when driving with GCMs than with reanalyses and that the biases are related to biases in sea surface temperature and sea-ice cover in the GCMs, and to how the GCMs represent the large-scale circulation. For the same model, Samuelsson et al. (2011) addressed some sources of systematic biases and how they have been mitigated somewhat in later versions. Kjellström et al. (2011) found that the ensemble mean is better than individual simulations at least for temperature but not necessarily for precipitation. Users designing an ensemble with limited computational resources may benefit from the results of Kendon et al. (2010), e.g. that for most areas, GCM uncertainty should be prioritised, using a reduced set of RCMs. For climate projections, Déqué et al. (2012) found that for Scandinavia, more (less) of the variability in winter precipitation (temperature) could be explained by the RCM than for other regions.

The results and discussion above show the need for RCM runs to be bias corrected in order to be locally applicable. In principle, all available climate model simulations can be bias-adjusted/calibrated to fit observed climate and thus can be used as input to hydrological models. However, the results in Fig. 2 for temperature and particularly in Fig. 3 for precipitation demonstrate that some models do not give a representative reproduction of annual amplitudes and annual cycles. The reason may be that some models may have significant biases in descriptions of sea-ice and snow cover in northern regions, and thus give misleading projections. To make sure that the dynamics in the models are realistic for Norway, we thus think it is wise to choose models that need small bias adjustments. Different bias adjustment methods exist based on statistical methods; see e.g. Ho et al. (2012), Watanabe et al. (2012) and White \& Toumi (2013). It is 
highly recommended that users of the climate projections are aware of the adjustment methods used, and particularly how they affect the climate signal, with special attention paid to the fact that the bias may incorrectly be assumed to be invariant over time.

\subsection{Further work}

The performance of the GCMs and RCMs over the Scandinavian region is dependent on the representation of the atmospheric circulation patterns. Norway typically experiences heavy precipitation coming from the south-west. Less common, but even more challenging are heavy precipitation events originating from the Atlantic Ocean, warming up over the European continent and reaching the Norwegian mainland from the south-east. Weather type classification was an important topic in the completed COST action 733 'Harmonisation and applications of weather type Classifications for European Regions' (http://cost733. met.no). To obtain a broader picture of the representation of the GCM and RCM runs in Scandinavia, and in southern Norway in particular, effort should be made to analyse how well the models capture the large-scale circulation patterns of recent historical re-analysis.

The work presented here is based on the CMIP3 archive and earlier results. Newer GCM runs are available (CMIP5 archive) as well as downscaled results (EURO-CORDEX; Jacob et al. 2013). Further analyses should be performed on these results.

\section{SUMMARY AND CONCLUSIONS}

Precipitation and temperature from RCMs are compared to reanalysis and observations over Scandinavia. Results are presented for 5 locations: OsloBlindern, Bergen-Florida, Trondheim-Værnes and Tromsø in Norway and Östersund-Frösön in Sweden.

To indicate which GCM-RCM-combination gives the best representation of the present climate over Scandinavia, a model ranking is provided. The performance measure used is the RMSD of mean monthly values and ratio of inter-annual variability. The data are compared for the selected 5 locations. The results show rather large differences between control runs and observations, demonstrating the need for bias adjustment of results downscaled from climate models. The main findings include the following:

- Compared to observations and re-analyses, the majority of the models seem to capture the annual temperature cycle rather well. Some models are exceptions, with RMSD of 5 to $9^{\circ} \mathrm{C}$.

- The regional models RACMO2 and RCA exhibit the smallest deviations from observed climate, but no model run performs best in all metrics. One RCM run has among the best representations of the precipitation cycle while at the same time being among the worst on temperature. It is highly recommended to apply an ensemble of model runs rather than 1 or 2 single model runs.

- Observed precipitation is less than in the models during the winter months. This may partly be caused by undercatch of snow in the precipitation gauges.

- Model ranking is tentative and should be considered only as an indicator of model performance for the present climate. It is not given that the model with the most representative control period results is the best also for future climate development.

- For studies of local climate change impacts, the results emphasize the need for GCM and RCM runs to be bias-corrected. It is important for users of climate projections to be aware of which methods are used, and how they change the absolute values as well as the future climate signal.

Acknowledgements. The present report was funded within the 'MIST-klimaprojeksjoner prosjekt', a collaboration project between Statkraft and MET Norway. The authors thank Eli Alfnes, Statkraft, for valuable discussions as well as the 3 anonymous reviewers whose comments contributed considerably to improving the manuscript . The ENSEMBLES data used in this work was funded by the EU FP6 Integrated Project ENSEMBLES (Contract GOCE-CT-2003-505539, www. ensembles-eu.org), whose support is gratefully acknowledged. We also acknowledge the E-OBS dataset from the ENSEMBLES project and the data providers in the ECA\&D project (www.ecad.eu).

\section{LITERATURE CITED}

Beldring S, Engen-Skaugen T, Førland EJ, Roald LA (2008) Climate change impacts on hydrological processes in Norway based on two methods for transferring regional climate model results to meteorological station sites. Tellus 60:439-450

Bergström S (1976) Development and application of a conceptual runoff model for Scandinavian catchments. PhD Thesis. SMHI Reports RHO No. 7, Norrköping

Bergström S (1992) The HBV model-its structure and applications. SMHI Reports RH No. 4, Norrköping

Bergström S, Carlsson B, Gardelin M, Lindström G, Pettersson A, Rummukainen M (2001) Climate change impacts on runoff in Sweden-assessments by global climate models, dynamical downscaling and hydrological modelling. Clim Res 16:101-112

Bladé I, Fortuny D, van Oldenborgh GJ, Liebmann B (2012) The summer North Atlantic Oscillation in CMIP3 models and related uncertainties in projected summer drying in 
Europe. J Geophys Res 117:D16104, doi:10.1029/2012JD 017816

> Boberg F, Berg P, Thejll P, Gutowski WJ, Christensen JH (2010) Improved confidence in climate change projections of precipitation further evaluated using daily statistics from ENSEMBLES models. Clim Dyn 35:1509-1520

Böhm U, Kücken M, Ahrens W, Block A and others (2006) CLM-the climate version of LM: brief description and long-term applications. COSMO Newsl 6:225-235

Cattiaux J, Yiou P, Vautard R (2012) Dynamics of future seasonal temperature trends and extremes in Europe: a multi-model analysis from CMIP3. Clim Dyn 38:1-16

Christensen JH, Christensen OB, Lopez P, van Meijgaard E, Botzet M (1996) The HIRHAM4 regional atmospheric climate model. DMI Sci Rep 96-4

> Christensen JH, Boberg F, Christensen OB, Lucas Picher P (2008) On the need for bias correction of regional climate change projections of temperature and precipitation. Geophys Res Lett 35:L20709, doi:10.1029/2008GL035694

> Christensen JH, Kjellström E, Giorgi F, Lenderink G, Rummukainen $M$ (2010) Weight assignment in regional climate models. Clim Res 44:179-194

> Collins M, Booth BB, Harris GR, Murphy JM, Sexton DM, Webb MJ (2006) Towards quantifying uncertainty in transient climate change. Clim Dyn 27:127-147

Collins M, Booth BBB, Bhaskaran B, Harris GR, Murphy JM, Sexton DMH, Webb MJ (2011) Climate model errors, feedbacks and forcings: a comparison of perturbed physics and multi-model ensembles. Clim Dyn 36: 1737-1766

de Elía R, Biner S, Frigon A (2013) Interannual variability and expected regional climate change over North America. Clim Dyn 41:1245-1267

Dee DP, Uppala SM, Simmons AJ, Berrisford P and others (2011) The ERA-Interim reanalysis: configuration and performance of the data assimilation system. QJR Meteorol Soc 137:553-597

> Déqué M, Somot S, Sanchez-Gomez E, Goodess CM, Jacob D, Lenderink G, Christensen OB (2012) The spread amongst ENSEMBLES regional scenarios: regional climate models, driving general circulation models and interannual variability. Clim Dyn 38:951-964

> Engen-Skaugen T (2007) Refinement of dynamically downscaled precipitation and temperature scenarios. Clim Change 84:365-382

> Førland EJ, Hanssen-Bauer I (2000) Increased precipitation in the Norwegian Arctic: true or false? Clim Change 46: 485-509

Founda D, Giannakopoulos C (2009) The exceptionally hot summer of 2007 in Athens, Greece-a typical summer in the future climate? Global Planet Change 67:227-236

Fowler HJ, Ekström M (2009) Multi-model ensemble estimates of climate change impacts on UK seasonal precipitation extremes. Int J Climatol 29:385-416

Giorgi F \& Mearns LO (1999) Introduction to special section: regional climate modeling revisited. J Geophys Res D 104:6335-6352

Giorgi F, Christensen J, Hulme M, von Storch H and others (2001) Regional climate information-evaluation and projections. Climate change 2001: the physical science basis. Contribution of Working Group to the Third Assessment Report of the Intergovernmental Panel on Climate Change. Cambridge University Press, Cambridge

Gudmundsson L, Bremnes JB, Haugen JE, Engen-Skaugen
T (2012) Technical note: downscaling RCM precipitation to the station scale using quantile mapping - a comparison of methods. Hydrol Earth Syst Sci 16:3383-3390

Haakenstad H, Reistad M, Haugen JE, Breivik Ø (2012) Update of the NORA10 hindcast archive for 2011 and a study of polar low cases with the WRF model. Rep No. 17/2012, Norwegian Meteorological Institute, Oslo

Hanssen-Bauer I, Drange H, Førland EJ, Roald L and others (2009) Klima i Norge 2100. In Hanssen-Bauer I (ed) Bakgrunnsmateriale til NOU Klimatilpasing. Norsk Klimasenter, Oslo (in Norwegian), p 69-95

> Hanssen-Bauer I, Førland EJ, Haugen JE, Tveito OE (2003) Temperature and precipitation scenarios for Norway: comparison of results from dynamical and empirical downscaling. Clim Res 25:15-27

Haugen JE, Haakenstad H (2006) Validation of HIRHAM version 2 with $50 \mathrm{~km}$ and $25 \mathrm{~km}$ resolution. RegClim Gen Tech Rep No. 9, Norwegian Meteorological Institute, Oslo, p 159-173

> Haylock MR, Hofstra N, Klein Tank AMG, Klok EJ, Jones PD, New M (2008) A European daily high-resolution gridded dataset of surface temperature and precipitation. J Geophys Res Atmos 113:D20119, doi:10.1029/2008JD010201

Ho CK, Stephenson DB, Collins M, Ferro CA, Brown SJ (2012) Calibration strategies: a source of additional uncertainty in climate change projections. Bull Am Meteorol Soc 93:21-26

> Jacob D (2001) A note to the simulation of the annual and inter-annual variability of the water budget over the Baltic Sea drainage basin. Meteorol Atmos Phys 77:61-73

Jacob D, Andrae U, Elgered G, Fortelius C and others (2001) A comprehensive model intercomparison study investigating the water budget during the BALTEX-PIDCAP period. Meteorol Atmos Phys 77:19-43

Jacob D, Bärring L, Christensen OB, Christensen JH and others (2007) An inter-comparison of regional climate models for Europe: model performance in present-day climate. Clim Change 81:31-52

Jacob D, Petersen J, Eggert B, Alias A and others (2013) EURO-CORDEX: new high-resolution climate change projections for European impact research. Reg Environ Change 14:563-578

Jones CG, Willén U, Ullerstig A, Hansson U (2004) The Rossby Centre regional atmospheric climate model. I. Model climatology and performance for the present climate over Europe. Ambio 33:199-210

Kendon EJ, Jones RG, Kjellström E, Murphy JM (2010) Using and designing GCM-RCM ensemble regional climate projections. J Clim 23:6485-6503

Kjellström E, Bärring L, Gollvik S, Hansson U and others (2005) A 140-year simulation of European climate with the new version of the Rossby Centre regional atmospheric climate model (RCA3). SMHI Rep Meteorol Climatol 108, SMHI, Norrköping. www.smhi.se/polopoly_fs/ 1.2104!RMK108\%5B1\%5D.pdf

Kjellström E, Boberg F, Castro M, Christensen JH, Nikulin G, Sánchez E (2010) Daily and monthly temperature and precipitation statistics as performance indicators for regional climate models. Clim Res 44:135-150

> Kjellström E, Nikulin G, Hansson U, Strandberg G, Ullerstig A (2011) 21st century changes in the European climate: uncertainties derived from an ensemble of regional climate model simulations. Tellus A 63:24-40

Landgren OA, Skaugen TE, Haugen JE, Førland EJ (2012) An evaluation of temperature and precipitation from 
global and regional climate models over Scandinavia. Rep No. 21a/2012, Norwegian Meteorological Institute, Oslo

Mearns LO, Arritt R, Biner S, Bukovsky MS and others (2012) The North American regional climate change assessment program: overview of phase I results. Bull Am Meteorol Soc 93:1337-1362

> Meehl GA, Covey C, Delworth T, Latif M and others (2007) The WCRP CMIP3 multi-model dataset: a new era in climate change research. Bull Am Meteorol Soc 88: 1383-1394

> Overland JE, Wang M, Bond NA, Walsh JE, Kattsov VM, Chapman WL (2011) Considerations in the selection of global climate models for regional climate projections: the Arctic as a case study. J Clim 24:1583-1597

Plummer DA, Caya D, Frigon A, Côté H and others (2006) Climate and climate change over North America as simulated by the Canadian RCM. J Clim 19:3112-3132

Racherla PN, Shindell DT, Faluvegi GS (2012) The added value to global model projections of climate change by dynamical downscaling: a case study over the continental US using the GISS ModelE2 and WRF models. J Geophys Res D 117:D20118, doi:10.1029/2012JD018091

Radu R, Déqué M, Somot S (2008) Spectral nudging in a spectral regional climate model. Tellus A 60:898-910

Reistad M, Breivik Ø, Haakenstad H, Aarnes OJ, Furevik BR, Bidlo JR (2011) A high-resolution hindcast of wind and waves for the North Sea, the Norwegian Sea and the Barents Sea. J Geophys Res C 116:C05019, doi:10.1029/ 2010JC006402

Roeckner E, Arpe K, Bengtsson L, Christoph M and others (1996) The atmospheric general circulation model ECHAM-4: model description and simulation of presentday climate. Report No. 218, MPI, Hamburg

Samuelsson P, Jones CG, Willén U, Ullerstig A and others (2011) The Rossby Centre Regional Climate model RCA3:

Editorial responsibility: Gouyu Ren, Beijing, China model description and performance. Tellus A 63:4-23

Sanchez E, Gallardo C, Gaertner MA, Arribas A, Castro M (2004) Future climate extreme events in the Mediterranean simulated by a regional climate model: a first approach. Global Planet Change 44:163-180

Shkolnik IM, Meleshko VP, Pavlova TV (2000) Regional hydrodynamical model for climate studies over Russia. Russ Meteorol Hydrol 4:32-49

Uppala SM, Kållberg PW, Simmons AJ, Andrae U and others (2005) The ERA-40 re-analysis. QJR Meteorol Soc 131: 2961-3012

van der Linden P, Mitchell JFB (eds) (2009) ENSEMBLES: climate change and its impacts: summary of research and results from the ENSEMBLES project. Met Office Hadley Centre, Exteter. http://ensembles-eu.metoffice.com/docs/ Ensembles_final_report_Nov09.pdf

van Meijgaard E, van Ulft LH, van de Berg WJ, Bosveld FC, van den Hurk BJJM, Lenderink G, Siebesma AP (2008) The KNMI regional atmospheric climate model RACMO, version 2.1. KNMI Tech Rep 302, KNMI, De Bilt. www. knmi.nl/bibliotheek/knmipubTR/TR302.pdf

> Walsh JE, Chapman WL, Romanovsky V, Christensen JH, Stendel M (2008) Global climate model performance over Alaska and Greenland. J Clim 21:6156-6174

> Watanabe S, Kanae S, Seto S, Yeh PJF, Hirabayashi Y, Oki T (2012) Intercomparison of bias-correction methods for monthly temperature and precipitation simulated by multiple climate models. J Geophys Res 117:D23114, doi:10.1029/2012JD018192

> White RH, Toumi R (2013) The limitations of bias correcting regional climate model inputs. Geophys Res Lett 40: 2907-2912

> Wood AW, Leung LR, Sridhar V, Lettenmaier DP (2004) Hydrologic implications of dynamical and statistical approaches to downscaling climate model outputs. Clim Change 62:189-216

Submitted: June 10, 2013; Accepted: May 8, 2014

Proofs received from author(s): July 26, 2014 